\title{
Mall Flicks - The Mall Boom in Turkey with an Unexpected Byproduct: The Movie Sector Expansion
}

\author{
Can Erbil ${ }^{1}$, Emin Köksal ${ }^{2}$ \& Cağlar Yurtseven ${ }^{2}$ \\ ${ }^{1}$ Department of Economics, Boston College, Chestnut Hill, Massachusetts, USA \\ 2 Department of Economics, Bahçeşehir University, İstanbul, Turkey \\ Correspondence: Can Erbil, Department of Economics, Boston College, Chestnut Hill, Massachusetts, USA.
}

Accepted: March 13, 2017

doi:10.5430/rwe.v8n1p1
Online Published: May 1, 2017

URL: https://doi.org/10.5430/rwe.v8n1p1

\begin{abstract}
Turkey has been experiencing a mall boom since the end of the 1990s. This boom's impacts are obvious on the construction, real estate and shopping sectors. However, surprisingly, this boom encouraged significant enlargement of the movie sector as well. This enlargement affects the cultural life of people, in addition to creating urbanization economies. In this paper, for the first time in the literature, effects of shopping mall expansion on the movie sector are studied. We construct a theoretical model and support our theoretical findings empirically, by employing a dynamic panel data estimation method and utilizing a unique dataset from Turkey. We show that without the mall boom, the recent fast expansion in the movie sector in Turkey would not be possible. Our findings may apply to similar metropolitan development booms in other emerging markets. (Note 1)
\end{abstract}

Keywords: mall, movie sector, dynamic panel data estimation method, cultural effect

(JEL Classification: L19, L82, R30)

\section{Introduction}

In Turkey, since the end of the 1990s, we have been observing a mall boom. The number of malls has risen from 26 in 1998 to 361 in 2015. As expected, this boom had a positive impact on the construction and real estate sector. (Note 2) The boom had a significant impact on the movie sector in Turkey as well, which was not expected in the initial phase of the mall expansion. In this paper, we first model the expansion in the movie sector, then we test our model by using data from the Turkish movie industry.

Similar to many malls in the world, the malls in Turkey have primarily been designed for shopping. One can shop for food, clothing, technology, cosmetics and much more. Shopping is the main activity, with there being few opportunities to socialize, especially for the youth. Socializing mainly occurs in the food courts and movie theaters. As the main entertainment component in malls, movie theaters have become popular along with the growing mall culture. The network effect of the friend circles has amplified this popularity, and the movie sector in Turkey has expanded six fold in 15 years. (Note 3)

This expansion has encouraged Turkish movie production firms as well. They have started to feature big productions for the first time since the emergence of TV in Turkey. As they find more and more viewers, they feature more and more movies. In 1998, the number of new Turkish movies was 14, it grew to 91 in 2015. (Note 4)

We hypothesize that the movie sector could not have reached its existing level without the boost from the malls. We believe that the economies created by movies through the malls, should be carefully studied. This has never been done in the literature before. For this purpose, first we review the choices of consumers in a general setting, and later with conditions exhibited in Turkey. After that, we construct our theoretical model and then test it empirically. Finally, we briefly conclude with a discussion of our findings and further research.

\section{Background and Literature Review}

Why have malls become popular?

Bloch et al. (1994) explained basic motivations for consumers to visit a mall using six categories. The first one is the mall enthusiasts, engaging in a wide range of behaviors that include a high level of purchasing, enjoyment of the mall aesthetics (e.g., physical design, appearance), and experiential consumption. The second one is escape, a relief from 
boredom and an escape from routine. The third one is exploration, tapping consumers' desires for variety or novelty and enjoyment of exploring new products or stores while in the mall. The fourth one is flow, reflecting a pleasurable absorption that is associated with losing track of time. The fifth one is knowledge or epistemic, referring to obtaining information about new stores and new products The last one is social affiliation, addressing the enjoyment of communicating and socializing with others (Kim, Kim, \& Kang, 2003). However, many of the motivations described above are valid for old pedestrian malls found mainly in the city centers of Turkey as well. What attracts people of Turkey, a developing country, to these modern malls? How has the number of malls risen from 26 to 334 in just 14 years?

First, due to high migration rates from rural areas to cities, public areas are crowded and dense in Turkey, congested with both pedestrian and vehicle traffic. People in the cities complain about the crowding, traffic and parking problems and lack of pedestrian safety in the city centers (Ödekan, 2001). Jackson (1998) states that "the contrived spaces of the shopping mall are a direct response to the perceived incivility of the city street". Due to traffic conditions and lack of infrastructure and maintenance in the city, this statement becomes very true for Turkey (Erkip, 2005). It is difficult to find even proper sidewalks in Turkey, which creates the major safety concern with the traffic congestion (Ödekan, 2001). Secondly, the privately protected malls give at least the perception of a safe zone against urban crime to the citizens. Thirdly, these malls respond to Turkish citizens who look for new modernity, with new consumption and leisure patterns provided by a more "civilized" space than the existing urban center and the street (Erkip, 2005).

Considering all these together, we can understand how spending spare time in malls has become extremely popular and why it is easier for consumers to benefit from a mall visit than a city center visit in Turkey.

Why theaters in the malls?

Academic research has revealed that many consumers are apt to make a decision regarding where to shop on the basis of their attitude toward a mix of stores and the mall or shopping center environment (Finn \& Louviere, 1990, 1996; Gentry \& Burns, 1977). The environment includes entertainment opportunities as well. There is even a word to define entertainment that people look for during shopping which is known as "retailtaintment" (Hoban, 1997). White (2008) describes many statistical details of the behavior of consumers in American shopping malls. $75 \%$ of families visiting a mall include a visit to the mall's family entertainment center which is the place for the movie complex.

After the initial phase of the boom, customers started looking to movie theaters in malls as the main entertainment source. Thus, movie theaters started to behave as anchor stores. "An anchor store is a store that increases, through its name's reputation, the traffic of shoppers at or near its location. Consumers, attracted by the anchor's name, are likely to visit the mall, and thus nearby stores' sales and profits are increased by the presence of the anchor." (Konishi \& Sandfort, 2003). This is why each mall in Turkey has a movie theater in it. Christensen et al. (1999) showed a positive relationship between entertainment and mall productivity which is defined as the sales per square foot. Considering this, we can understand why malls reserve places for movie theaters in general and why each mall in Turkey has movie theaters. Due to their positive effect on mall productivity, through acting as anchor stores, as Pashigian \& Gould (1998) found, movie theaters at shopping malls can receive substantial rent subsidies. Therefore, this leads us to believe, movie theaters in malls have a cost advantage over similar size movie theaters in city centers.

In fact, the two aforementioned issues, (1) providing easier benefits to consumers and (2) offering a cost advantage, are the essential features of mall movie theaters. Based on these two features, our theoretical model suggests propositions for an empirically testable model.

\section{The Theoretical Model}

In this section, we put a theoretical model that explains competition between two movie theaters by showing how differences in costs and benefits offered to consumers may help to enlarge the market.

In the model, we assume two movie theaters ( $T_{k}$ where $k \in\{$ West, East $\left.\}\right)$ compete to attract consumers. In reality, in Turkey, featured movies are identical and ticket prices $(p)$ are almost the same. Therefore, we assume those movie theaters compete with benefits $\left(b_{k}\right)$ that they offer to their customers. Those benefits may be in the form of direct benefits such as quality of halls/screens, free car parking, discounts in nearby restaurants, shopping stores, or groceries. In addition, the benefits may be in the form of indirect benefits such as availability, nearness of facilities, and safety. To transfer those benefits to each customer we assume that each movie theater has a discount factor $\left(\beta_{k}\right)$. We also assume that each movie theater has a cost $\left(c_{k}\right)$ per consumer (Note 5) to offer movie screenings.

Then, $k^{\text {th }}$ movie theater's profit function appears as: 


$$
\Pi_{k}\left(b_{k}\right)=\left(p-c_{k}-\beta_{k} b_{k}\right) N_{k}
$$

where $p$ is movie ticket price and $N_{k}$ represents fraction of population that goes to movie theater $k$.

Movie theater consumers consist of a variety of movie viewers. In addition to movie watching, they gain positive utility by being able to park their cars, to visit nearby stores, groceries and restaurants. However, their valuation of going to a movie theater varies from person to person for a variety of reasons. A Hotelling (1929) location specification is introduced to specify them. More specifically, consumers are assumed to be uniformly distributed over the interval $[0,1]$. In addition, there exists a unit transportation cost $(m)$ to go to a movie theater $\left(T_{k}\right)$.

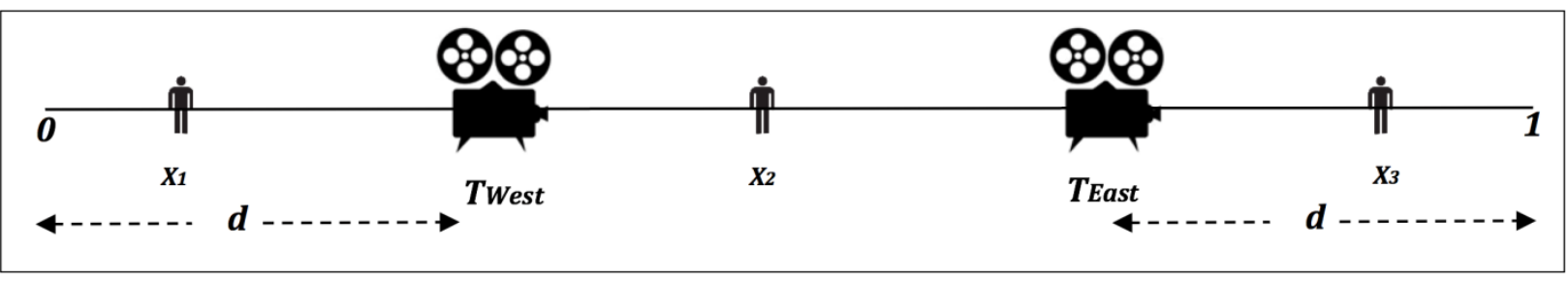

Figure 1. Location specification without market coverage

However, to avoid the full market coverage, we locate the movie theaters at a distance $d<\frac{1}{2}$ from the endpoints of the interval, over which consumers are uniformly distributed. It is assumed that $d$ and $m$ are sufficiently large to ensure that the market is never covered. Three marginal consumers (at $x_{1}, x_{2}$ and $x_{3}$ ) are considered, as shown in Figure 1 .

The marginal consumer, located at $x_{1}$, is indifferent between going to $T_{W e s t}$ and staying out of the market. The marginal consumer, located at $x_{2}$, is indifferent between the two movie theaters. And the consumer, located at $x_{3}$, is indifferent between staying out of the market and going to $T_{\text {East }}$.

A consumer, located at $x_{1}$, pays the transportation cost of $m\left(d-x_{1}\right)$ going to $T_{W e s t}$. A consumer, located at $x_{2}$, pays the transport cost of $t\left(x_{2}-d\right)$ going to $T_{W e s t}$ and $m\left(1-d-x_{2}\right)$ going to $T_{E a s t}$. Finally a consumer, located at $x_{3}$, pays the transportation cost of $m\left(x_{3}-(1-d)\right)$ going to $T_{\text {East }}$.

Then, $n^{\text {th }}$ (where $n \in\{1,2,3\}$ ) consumer's utility function from going to a movie appears as follows:

$$
\begin{gathered}
U_{1, \text { West }}=v+b_{\text {West }}-p-m\left(d-x_{1}\right) \\
U_{2, \text { West }}=v+b_{\text {West }}-p-m\left(x_{2}-d\right) \\
U_{2, \text { East }}=v+b_{\text {East }}-p-m\left(1-d-x_{2}\right) \\
U_{3, \text { East }}=v+b_{\text {East }}-p-m\left(x_{3}-(1-d)\right)
\end{gathered}
$$

where $v$ (Note 6) indicates intrinsic value of going to a movie theatre for a consumer.

Using the above equation system, the marginal consumers at $x_{n}$, who are indifferent to going to $T_{k}$, and going to $T_{k}$ or remaining outside, are defined as:

$$
x_{1}=\frac{p+d m-v-b_{W e s t}}{m}, x_{2}=\frac{m+b_{\text {West }}-b_{\text {East }}}{2 m} \text {, and } x_{3}=\frac{-p+m-d m+v+b_{\text {East }}}{m} .
$$

Since $N_{\text {West }}=x_{2}-x_{1}$, and $N_{\text {East }}=x_{3}-x_{2}$, one can get

$$
N_{\text {West }}\left(b_{k}\right)=\frac{m(1-2 d)+2(v-p)+3 b_{\text {West }}-b_{\text {East }}}{2 m}
$$




$$
N_{\text {East }}\left(b_{k}\right)=\frac{m(1-2 d)+2(v-p)+3 b_{\text {East }}-b_{\text {West }}}{2 m}
$$

Considering the demand, $T_{k}$ 's problem is to set the optimal benefit level that maximizes its profit mentioned in equation (1). The first order conditions $\left(\frac{d \Pi_{k}}{d b_{k}}=0\right)$ give (Note 7):

$$
\begin{aligned}
& b_{\text {West }}^{*}=\frac{18 \beta_{\text {East }}\left(p-c_{\text {West }}\right)+3 \beta_{\text {West }}\left(p-c_{\text {East }}\right)}{35 \beta_{\text {Mall }} \beta_{\text {City }}}+\frac{2(p-v)-m(1-2 d)}{5} \\
& b_{\text {East }}^{*}=\frac{18 \beta_{\text {West }}\left(p-c_{\text {East }}\right)+3 \beta_{\text {East }}\left(p-c_{\text {West }}\right)}{35 \beta_{\text {West }} \beta_{\text {East }}}+\frac{2(p-v)-m(1-2 d)}{5}
\end{aligned}
$$

which are again positive for sufficiently large $m$ values that requires sufficiently differentiated consumers.

Then we can derive the market participation of consumers as,

$$
\begin{aligned}
& N_{\text {West }}^{*}=\frac{51 \beta_{\text {East }}\left(p-c_{\text {West }}\right)+3 \beta_{\text {West }}\left(3\left(c_{\text {East }}-p\right)+7 \beta_{\text {East }}(2(v-p)+m(1-2 d))\right)}{70 m \beta_{\text {West }} \beta_{\text {East }}} \\
& N_{\text {East }}^{*}=\frac{51 \beta_{\text {West }}\left(p-c_{\text {East }}\right)+3 \beta_{\text {East }}\left(3\left(c_{\text {West }}-p\right)+7 \beta_{\text {West }}(2(v-p)+m(1-2 d))\right)}{70 m \beta_{\text {West }} \beta_{\text {East }}}
\end{aligned}
$$

which are positive again for sufficiently large $m$ values.

Since our interest is the share of total movie viewers in the whole population, we get the sum $N^{*}\left(=N_{\text {West }}^{*}+N_{\text {East }}^{*}\right)$ as

$$
N^{*}=\frac{3\left(\beta_{\text {East }}\left(p-c_{\text {West }}\right)+\beta_{\text {West }}\left(p-c_{\text {East }}\right)+\beta_{\text {West }} \beta_{\text {East }}(2(v-p)+m(1-2 d))\right)}{5 m \beta_{\text {West }} \beta_{\text {East }}} .
$$

Proposition 1: Any decrease in the discount factor of transferring benefits $\left(\beta_{k}\right)$ and/or cost per viewer $\left(c_{k}\right)$, increases the share of viewers in the population.

Proof. Taking the partial derivative of equation (12) gives us,

$$
\begin{gathered}
\frac{\partial N^{*}}{\partial \beta_{k}}=-\frac{3\left(p-c_{k}\right)}{5 t \beta_{k}^{2}}<0 \\
\frac{\partial N^{*}}{\partial c_{k}}=-\frac{3}{5 t \beta_{k}}<0
\end{gathered}
$$

which are both negative. Q.E.D.

Essentially, with Proposition 1 we showed that as the cost per viewer and/or cost of transferring direct and indirect benefits to the consumers decrease, share of viewers in the population increases.

The remaining question that has to be answered is how this duopoly model behaves when we extend it with an additional movie theater. Appendix A offers such an extension. The following propositions are obtained through this extended model.

Proposition 2a: An additional movie theater $\left(T_{M i d}\right)$ always increases the share of viewers in the population by enlarging towards the west-side of the market if it has a lower discount factor of transferring benefits and a lower cost per viewer than the movie theater $T_{\text {East }} .\left(\beta_{\text {Mid }} \leq \beta_{\text {East }}\right.$ and $\left.c_{\text {Mid }} \leq c_{\text {East }}\right)$ 
Proposition 2b: An additional movie theater always increases the share of viewers in the population by enlarging towards the east-side of the market, if it has lower or equal discount factor of transferring benefits and cost per viewer than the movie theater $T_{\text {West }} .\left(\beta_{\text {Mid }} \leq \beta_{\text {West }}\right.$ and $\left.c_{\text {Mid }} \leq c_{\text {West }}\right)$

Proof. See Appendix A.

Proposition $2 \mathrm{a}$ and $2 \mathrm{~b}$ give us the necessary conditions for an increase in the share of viewers in the population through an additional movie theater. Those conditions indicate that a more or equally effective additional competitor always forces the existing theaters to enlarge the market on their side.

The general idea we get through the theoretical model suggest that if a newcomer can provide benefits easier and its cost per viewer is lower than the existing ones it enlarges the market. Based on the literature (Note 8) and real world observations, one can argue that benefits are transferred less costly by mall theaters and subsidized expenses of mall theaters are lower. Then, based on Proposition 1, one can make an inference that a mall type movie theater can raise the viewer share in the population more than a city type movie theater can do. Furthermore, Proposition 1 may also be useful in making a comparison to evaluate what happens if both theaters have the same characteristics in terms of cost of transferring benefits and cost per viewer. One can easily infer that having two mall type theaters increases the share of viewers in the population more than two city type theaters.

As put through Propositions $2 \mathrm{a}$ and $2 \mathrm{~b}$, if the additional movie theater is more or equally effective than the earlier competitor, then the profit maximizer theater is forced to extend its marginal consumer on its side. Based on market research and the literature, as mentioned before, malls have advantages over city theaters in terms of costs and benefits offered. Hence, we can interpret the above theoretical finding as follows: mall theaters help enlarge the movie market more than the city theaters do. Without loss of generality, one can argue that as long as the additional movie theater is a mall type, the share of viewers in the population increases.

\section{The Econometric Model}

\subsection{The Empirical Specification}

Our theoretical model suggests a number of factors that influence the ratio of movie theater viewers in the population (Equation (12)). We are particularly interested in the influences of benefits offered by movie theaters. We show that the cost per viewer and discount factor of transferring benefits are the key determinants of market participation. Based on our theoretical model and propositions, we hypothesize that mall movie theaters increase the share of viewers in the population.

To test this hypothesis, we use a reduced-form specification based on equation (12). For empirical purposes, we identify a market as a province. To indicate our dependent variable, the viewer share in the population, we use the ratio of number of tickets sold to the population in province $i$ in year $t$. Since our key measures, cost per viewer and discount factor of transferring benefits are not available, as previously described in detail, we use the ratio of mall screens to the total number of screens in a province as a proxy measure of relative discount factor for benefits and average cost of movie theater operations. We expect discount factor for benefits and average costs to decline as the share of mall theater screens increases.

Following Dardis et al. (1994), we use the real GDP per capita, ratio of young population and tertiary education in province $i$ in year $t$ as proxies of valuation of consumers. Dardis et al. (1994) show that, as the levels of income, education and ratio of young people in the population increase, people become more likely to spend for leisure activities in general. Besides the variables proposed by Dardis et al. (1994), past realization of going to a movie theater can also be an appropriate indicator as a proxy of consumer valuation. (Craig et al. (2015)) Therefore we use the lagged dependent variable, the ratio of number of tickets sold to the population, as an additional explanatory variable.

In addition, for the specific case of Turkey, we claim that, an ordinary person has more interest in domestic movies. This claim is based on the observation that domestic movies and series attract more viewers when they are broadcasted on TV. They also have more viewers on the internet. (Note 9) In addition for the last 10 years, all the most viewed movies in theaters in Turkey are domestic. (Note 10) Valuation of domestic movies might be playing a role in this choice. Hence, we expect the share of viewers to increase, as income, education, ratio of young people and the number of domestic movies increase.

Movie tickets are not free. Even if there is no significant variation in the price of tickets in a particular province, there are slight differences among the different provinces of Turkey. Hence, in our data set we include a price variable. It is the real index for the entertainment prices in province $i$, in year $t$.

We use a linear specification that, relates the aforementioned explanatory variables to the ratio of number of tickets 
sold to the population:

$$
N_{i t}=\alpha_{0 i}+\alpha_{1} N_{i, t-n}+\alpha_{2} \text { malls }_{i, t}+\alpha_{3} \text { inc }_{i, t}+\alpha_{4} \text { dmovie }_{i, t}+\alpha_{5} e d u_{i, t}+\alpha_{6} \text { young }_{i, t}+\alpha_{7} \text { price }_{i, t}+\varepsilon_{i, t} .
$$

Table 1. Variables

\begin{tabular}{cl}
\hline Variables & Explanations \\
\hline $\boldsymbol{N}_{\boldsymbol{i}, \boldsymbol{t}}$ & ratio of tickets sold to population in province $\boldsymbol{i}$ in year $\boldsymbol{t} .(\%)$ \\
$\boldsymbol{m a l l s}_{\boldsymbol{i}, \boldsymbol{t}}$ & ratio of mall screens to all screens in province $\boldsymbol{i}$ in year $\boldsymbol{t}$. (\%) \\
$\boldsymbol{i n c}_{\boldsymbol{i}, \boldsymbol{t}}$ & real GDP per person in province $\boldsymbol{i}$ in year $\boldsymbol{t}$. \\
$\boldsymbol{d m o v i ~}_{\boldsymbol{i}, \boldsymbol{t}}$ & number of domestic movies to total number of movies featured in province $\boldsymbol{i}$ in year $\boldsymbol{t}$. \\
$\boldsymbol{e d u}_{\boldsymbol{i}, \boldsymbol{t}}$ & $\%$ of 15+ population who have at least a high school degree in province $\boldsymbol{i}$ in year $\boldsymbol{t}$. \\
$\boldsymbol{y o u n g}_{\boldsymbol{i}, \boldsymbol{t}}$ & $\%$ of people between 15-40 to total in province $\boldsymbol{i}$ in year $\boldsymbol{t}$. \\
$\boldsymbol{p r i c e}_{\boldsymbol{i}, \boldsymbol{t}}$ & index for the real entertainment prices in province $\boldsymbol{i}$ in year $\boldsymbol{t}$. \\
\hline
\end{tabular}

A summary of the variables used in the estimation is presented in Table 1.

However, at least three econometric problems may arise from estimating equation (15). First, the price variables in price $_{i t}$ are endogenous. Then, these regressors may be correlated with the error term. Second, time-invariant province characteristics (fixed effects) may be correlated with the explanatory variables. Third, the presence of lagged dependent variable may be a probable cause of autocorrelation. A candidate solution for the first and the second problems might be the usage of fixed-effects instrumental variable estimation. However, we lack suitable instrumental variables changes of which are associated with changes in the index for the entertainment prices, but do not lead to direct changes in the ratio of number of tickets sold to the population.

Then, we decided to use the dynamic panel data estimation method which was created by Holtz-Eakin, Newey, \& Rosen (1988) and later developed by Arellano \& Bond (1991), Arellano \& Bover (1995), and Blundell \& Bond (1998). This method comes with many advantages. First, this method allows us to use endogenous variables as pre-determined which is not correlated with the error term. Second, it removes fixed-effect by transforming regressors using difference generalized method of moments (GMM). Third, it allows us to use lagged dependent variable to instrument with its past levels.

This estimation method is also reported to be ideal for data sets which consist of a short time dimension and a larger province dimension (Roodman, 2009). Our data set exactly satisfies these characteristics. We resorted to the two-step system GMM estimator. (Note 11)

\subsection{Data}

In this study, we use panel data for each province of Turkey, for the years 2003-2012. TurkStat (Turkish Statistical Institution) provides the total number of screens in the movie theaters. However, it does not provide any information about the location of these movie theaters. That is, in Turkey, there is no publicly available data that gives the separate number of mall screens and city screens in a province. 


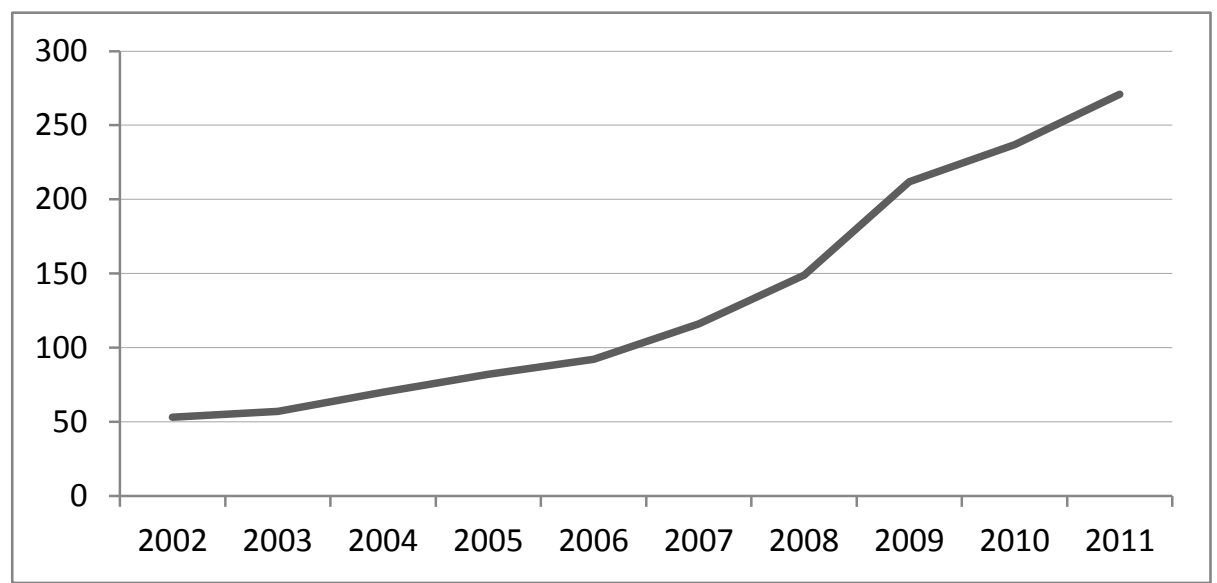

Figure 2. Total number of malls in Turkey

Source: Mall Investors Association of Turkey

However, as mentioned before, the ratio of city screens to mall screens is a key variable in this study. Based on this necessity, we obtained data from the Mall Investors Association of Turkey See, Figure 2). The data provides the name of the malls in each city of Turkey and their opening year and contact information.

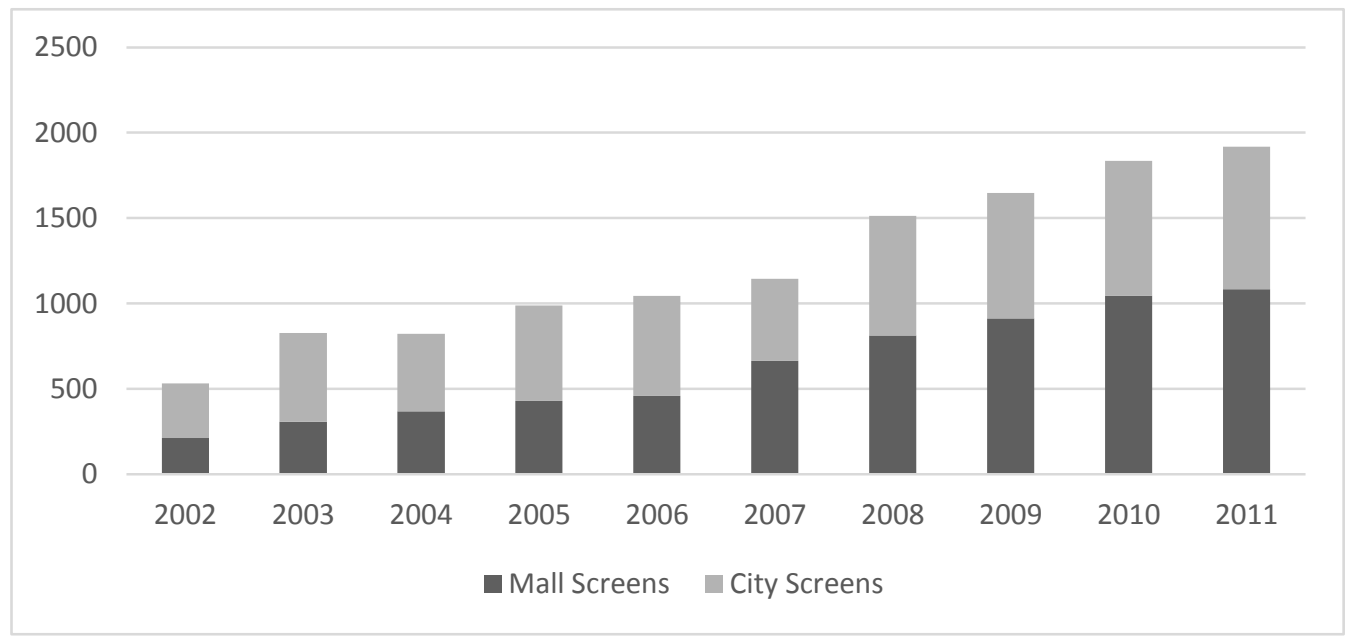

Figure 3. Total number of city and mall screens

Source: Own calculations

Using this information, we contacted movie theaters in each mall. Each movie theater provided us the total number of screens in each year. By adding the screens in each mall, we calculated the number of mall screens in each province, in each year. The difference from the total numbers provided by TurkStat gives us the number of city screens in each city, in each year. Hence, we are able to calculate the mall screen to total screen ratio. (Note 12) The total number of city and mall screens in the whole country is given in Figure 3.

TurkStat directly provides all other socio-economic (including the price index) and movie related data in this study. All these data are in panel form. That is, we have average values for each province and for each year. However TurkStat does not directly provide data of some per capita variables. Real GDP (Note 13), total number of viewers and province population data are taken from TurkStat. (For the years between 2003 and 2006, instead of actual population figures, only projections prepared by TurkStat are available. For that period the projected numbers are used in the estimation.) From these data we calculate the personal real income and viewer rates for each province for the time period 2003-2012. Descriptive statistics for the variables used are presented in the Appendix B. 


\subsection{Estimation Results}

The results of the estimation are shown in Table 2.

Table 2. Estimation results

\begin{tabular}{|c|c|c|c|c|}
\hline Variables & $I$ & $I I$ & $I I I$ & $I V$ \\
\hline \multicolumn{5}{|l|}{$\mathrm{N}$} \\
\hline \multirow[t]{2}{*}{ L1 } & $0.4472 * * *$ & $0.4489 * * *$ & $0.4485^{* * *}$ & $0.4622 * * *$ \\
\hline & $(.0668)$ & $(.0674)$ & $(0.0659)$ & $(0.0670)$ \\
\hline \multirow[t]{2}{*}{ L2 } & $0.2236 * *$ & $0.2228 * *$ & $0.2230 * *$ & $0.2292 * *$ \\
\hline & $(0.0683)$ & $(0.0696)$ & $(0.0697)$ & $(.0700)$ \\
\hline \multirow[t]{2}{*}{ malls } & $0.0949 * *$ & $0.0920 * *$ & $0.0911 * *$ & $0.0907 * *$ \\
\hline & $(0.0286)$ & $(0.0281)$ & $(0.0281)$ & $(0.0289)$ \\
\hline \multirow[t]{2}{*}{ dmovie } & $0.0001 * *$ & $0.0001 *$ & $0.0001^{*}$ & $0.0001 *$ \\
\hline & $(0.0000)$ & $(0.0000)$ & $(0.0000)$ & $(0.0000)$ \\
\hline \multirow[t]{2}{*}{ edu } & $0.41351^{* *}$ & $0.4120^{* *}$ & $0.3901 * *$ & \\
\hline & $(0.1387)$ & $(0.1452)$ & $(0.1223)$ & \\
\hline \multirow[t]{2}{*}{ inc } & 0.00001 & 0.00001 & & \\
\hline & $(0.0000)$ & $(0.0000)$ & & \\
\hline \multirow[t]{2}{*}{ young } & 0.1589 & & & \\
\hline & $(0.2390)$ & & & \\
\hline \multirow[t]{2}{*}{ eduyoung } & & & & $0.6412 *$ \\
\hline & & & & $(0.2699)$ \\
\hline \multirow[t]{2}{*}{ price } & 0.0026 & 0.0027 & 0.0026 & 0.0029 \\
\hline & $(0.0015)$ & $(0.0015)$ & $(0.0015)$ & $(0.0015)$ \\
\hline \multirow[t]{2}{*}{ time } & 0.0068 & 0.0075 & 0.0071 & 0.0077 \\
\hline & $(0.0069)$ & $(0.0068)$ & $(0.0066)$ & $(0.0069)$ \\
\hline year dummies & YES & YES & YES & YES \\
\hline \# of obs. & 567 & 567 & 567 & 567 \\
\hline \# of groups & 76 & 76 & 76 & 76 \\
\hline \# of instruments & 75 & 74 & 73 & 73 \\
\hline Hansen stat (Note 14) & 66.2098 & 66.5791 & 66.3296 & 65.2889 \\
\hline$A R(1)$ & $-3.3551 * * *$ & $-3.3526^{* * *}$ & $-3.3569 * * *$ & $-3.3522 * * *$ \\
\hline$A R(2)$ & 0.0801 & 0.0760 & 0.0709 & 0.0093 \\
\hline
\end{tabular}

Note: The numbers in parenthesis represent the standard errors. $* * *$ and $* * *$ indicate the significance at the $5 \%, 1 \%$ and $0.1 \%$ levels, respectively.

When we examine the results above that we get through dynamic panel data estimation, we easily observe the importance of past realizations, ratio of mall screens to total number of screens, education, and total number of domestic movies featured as determinants of viewer share in the population. In line with the theory, these variables have the expected positive signs. Therefore, we can claim that as the education, mall movie theater ratio and number of domestic movies increase, the tendency of going to a movie increases. The results are significant with the different forms employed and they are robust. When we check the results in terms of each independent variable employed, we also observe interesting results.

First, we observe that the mall screens ratio, which is the key variable for our purposes, is significant and has the 
expected sign implied by the model. The theory says that mall theaters have an advantage over city movie theaters when it comes to cost and the provision of benefits. Hence, we show in the theoretical model that more people go to the movies from a given province if the ratio of mall screens to total number of screens increases. The empirical results strengthen this proposition. When this ratio increases by 1 percent, viewer share in a province increases by 0.10 percent. This finding is important in the sense that, it provides empirical support for the propositions stated in the theoretical section.

As the number of domestic movies increases, we observe an increase in the viewer share. The coefficient is positive and significant. This result is expected when we consider the fact that Turkish people find Turkish movies more appealing especially in terms of the scenario and the characters. The top 10 most viewed movies in Turkey are all domestic. Turkey is at the top of the list among all European countries in terms of the share of viewers who viewed domestic movies. (Note 15) Hence, in the last 10 years, as more domestic movies were featured in the theaters, more people started to go to the movies. Considering this fact, this result does not come as a surprise. (Note 16)

The variable for education has the expected positive sign which means that as average education increases in a province, viewer share also increases in that province. It is significant as well. In line with the literature more educated people are more likely to spend for leisure activities. When the percentage of high school graduates increases by 1 percent, movie viewer share in a given province increases by 0.5 percent. That is when we consider the growth in the ratio of high school graduates in Turkey, we can claim that education plays an important role in the recent movie sector expansion.

Income per capita has the expected positive sign. As increases in a province, more people are likely to go to the movies. However, the income per capita increase in Turkey does not seem to play a significant role. In the recent expansion of the sector, cultural factors seem to dominate economic improvements by their effects on the movie sector expansion.

Just being young does not seem to be a significant determinant of movie viewer ratio as well. However, when we include an interaction variable (education*young population) we observe its significance with a positive sign. Educated (at least high school graduates) young people have a higher likelihood of going to the movies. Effect of college students might be playing a significant role in this result with their high attendance in the movie theaters.

The variable for price of tickets is insignificant. This may be because there is so little variation in price among movie theaters in different provinces of Turkey. (Note 17) We estimate the model also by including a trend variable. The trend variable is insignificant as well.

\section{Discussion}

In this paper, considering our theoretical and empirical findings, we claim that the recent expansion of the movie sector in Turkey would not be possible at its existing rate, without the mall boom. As new screens opened up in malls, the ratio of mall to all screens has improved significantly and it is still increasing. This helps movie theaters and producers attract new viewers to the industry. (Note 18)

In addition to an increase in the number of movie theaters, the number of domestic movies produced has risen from 14 to 86 in the last 15 years due to the expanding number of viewers in the population. Shortly, the boom has helped the entire sector.

Malls are heavily criticized by environmentalists because of their vast environmental footprint and the additional traffic they create. When externalities are considered, the literature generally focuses on the impact on real estate, construction and shopping sectors. With this paper we believe that, from now on, when conducting a cost-benefit analysis, economists will also consider the less studied positive externalities that are covered in this paper, which are beneficial to the entertainment sector. Further empirical evidence from other emerging market metropolitans would be the subject of future research.

\section{References}

Arellano, M., \& Bond, S. (1991). Some tests of specification for panel data: Monte Carlo evidence and an application to employment equations. The Review of Economic Studies, 58(2), 277. https://doi.org/10.2307/2297968

Arellano, M., \& Bover, O. (1995). Another look at the instrumental variable estimation of error-components models. Journal of Econometrics, 68(1), 29-51. https://doi.org/10.1016/0304-4076(94)01642-D

Bloch, P. H., Ridgway, N. M., \& Dawson, S. A. (1994). The shopping mall as consumer habitat. Journal of Retailing, 70(1), 23-42. https://doi.org/10.1016/0022-4359(94)90026-4 
Blundell, R., \& Bond, S. (1998). Initial conditions and moment restrictions in dynamic panel data models. Journal of Econometrics, 87(1), 115-143. https://doi.org/10.1016/S0304-4076(98)00009-8

Christiansen, T., Comer, L., Feinberg, R., \& Heikki, R. (1999). The Effects of Mall Entertainment Value on Mall Profitability. Journal of Shopping Center, 6(2), 7-22.

Craig, C. S., Greene, W. H., \& Versaci, A. (2015). E-Word of Mouth: Early Predictor of Audience Engagement. Journal of Advertising Research, 55(1), 62-72. https://doi.org/10.2501/JAR-55-1-062-072

Dardis, R., Soberon-Ferrer, H., \& Patro, D. (1994). Analysis of leisure expenditures in the United States. Journal of Leisure Research, 26(4), 309-321.

Erkip, F. (2005). The rise of the shopping mall in Turkey: the use and appeal of a mall in Ankara. Cities, 22(2), 89-108.

Finn, A., \& Louviere, J. (1990). Shopping-center patronage models. Fashioning a consideration set segmentation solution. Journal of Business Research, 21(3), 259-275. https://doi.org/10.1016/0148-2963(90)90032-9

Finn, A., \& Louviere, J. J. (1996). Shopping center image, consideration, and choice: Anchor store contribution. Journal of Business Research, 35(3), 241-251. https://doi.org/10.1016/0148-2963(95)00129-8

Finn, A., McQuitty, S., \& Rigby, J. (1994). Residents' acceptance and use of a mega-multi-mall: West Edmonton Mall evidence. International Journal of Research in Marketing, 11(2), 127-144. https://doi.org/10.1016/0167-8116(94)90024-8

Gentry, J. W., \& Burns, A. C. (1977). How 'Important' are Evaluative Criteria in Shopping Center Patronage?. Journal of Retailing Retailing, 53, Winter, 73-86.

Hoban, S. (1997). Retail Entertainment: New Developments Are Making Shopping Fun Again. Commercial Investment Real Estate, March-April, 24-29.

Holtz-Eakin, D., Newey, W., \& Rosen, H. S. (1988). Estimating Vector Autoregressions with Panel Data. Econometrica, 56(6), 1371-1395. https://doi.org/10.2307/1913103

Hotelling, H. (1929). Stability in competition. The Economic Journal, 39(153), 41-57. https://doi.org/10.1007/978-1-4613-8905-7_4

Jackson, P. (1998). Domesticating the street: The contested spaces of the high street and the mall. In N.R. Fyfe (Ed.), Images of the Street: Planning, Identity and Control in Public Space (pp.176-191). London and New York: Routledge.

Kang, J., Kim, Y., \& Tuan, W. (1996). Motivational factors of mall shoppers: Effects of ethnicity an age. Journal of Shopping Center Research, 3(1), 7-31.

Kim, Y.-K., Kim, E. Y., \& Kang, J. (2003). Teens' Mall Shopping Motivations: Functions of Loneliness and Media Usage. Family and Consumer Sciences Research Journal, 32(2), 140-167. https://doi.org/10.1177/1077727X03032002004

Konishi, H., \& Sandfort, M. T. (2003). Anchor stores. Journal of Urban Economics, 53(3), 413-435. https://doi.org/10.1016/S0094-1190(03)00002-0

Ödekan, A. (2001, April). İstanbul'da yaya hakk1 var mı? İstanbul, 37, 48-51.

Pashigian, B. P., \& Gould, E. D. (1998, April). Internalizing Externalities: The Pricing of Space in Shopping Malls. Journal of Law and Economics, 41, 115-142. https://doi.org/10.1086/467386

Roodman, D. (2009). How to do xtabond2: An introduction to difference and system GMM in Stata. Stata Journal, 9(1), 86-136.

White, R. (2008). The Role of Entertainment in Shopping Centers \& Malls. White Hutchinson Leisure \& Learning Group White Paper. Retrieved January 11, 2016, from https://www.whitehutchinson.com/leisure/articles/ Role_of_Entertainment.shtml 


\section{Appendix A}

In this appendix, we extend our theoretical model through adding a new movie theater to obtain necessary conditions for the enlargement of the market.

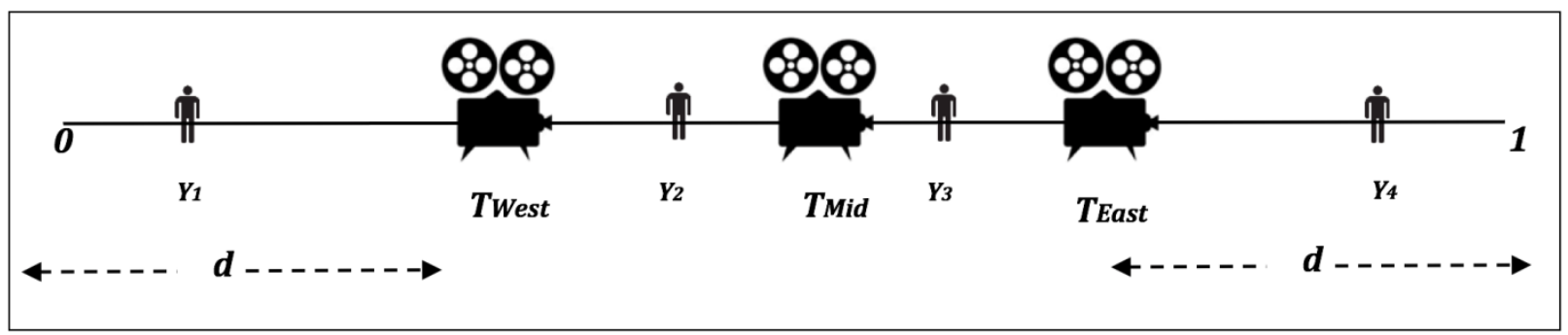

Figure A1. Location specification with an additional movie theater

In the model, we have an additional movie theater $\left(T_{M i d}\right)$ which competes with the existing theaters to attract consumers. This additional movie theater is situated between the other two theaters as shown in Figure A1. (Note 19) Again, to avoid the full market coverage, we locate the movie theaters at a distance $d<\frac{1}{2}$ from the endpoints of the interval, over which consumers are uniformly distributed. Four marginal consumers (at $y_{1}, y_{2}, y_{3}$ and $y_{4}$ ) are considered.

The marginal consumer located at $y_{1}$ is indifferent between going to $T_{W e s t}$ and staying out of the market. The consumer located at $y_{2}$ is indifferent between going to $T_{W e s t}$ and $T_{\text {Mid }}$. The marginal consumer located at $y_{3}$ is indifferent between going to $T_{M i d}$ and $T_{E a s t}$. And the marginal consumer located at $y_{4}$ is indifferent between staying out of the market and going to $T_{\text {East }}$.

Then, $n^{\text {th }}$ (where now $n \epsilon\{1,2,3,4\}$ ) consumer's utility function from going to a movie theater appears as follows:

$$
\begin{gathered}
U_{1, \text { West }}=v+b_{\text {West }}-p-m\left(d-y_{1}\right) \\
U_{2, \text { West }}=v+b_{\text {West }}-p-m\left(y_{2}-d\right) \\
U_{3, \text { Mid }}=v+b_{\text {Mid }}-p-m\left(\frac{1}{2}-y_{2}\right) \\
U_{3, \text { Mid }}=v+b_{\text {Mid }}-p-m\left(y_{3}-\frac{1}{2}\right) \\
U_{3, \text { East }}=v+b_{\text {East }}-p-m\left(1-d-y_{3}\right) \\
U_{4, \text { East }}=v+b_{\text {East }}-p-m\left(y_{4}-(1-d)\right)
\end{gathered}
$$

where $v$ (Note 20) indicates the intrinsic value of a consumer from going to a movie theater.

Using the above equation system, the consumers at $y_{n}$, can be defined as:

$$
\begin{aligned}
& y_{1}=\frac{p+d m-v-b_{\text {West }}}{m}, \quad y_{2}=\frac{m+2\left(d m+b_{\text {West }}-b_{\text {Mid }}\right)}{4 m}, \quad y_{3}=\frac{3 m-2\left(d m+b_{\text {West }}-b_{\text {Mid }}\right)}{4 m}, \\
& y_{4}=\frac{v-p+m-d t+b_{\text {East }}}{m} .
\end{aligned}
$$

Since $N_{\text {West }}=y_{2}-y_{1}, N_{\text {Mid }}=y_{3}-y_{2}$, and $N_{\text {East }}=y_{4}-y_{3}$, one can get 


$$
\begin{gathered}
N_{\text {West }}\left(b_{k}\right)=\frac{4(v-p)+m(1-2 d)+6 b_{\text {West }}-2 b_{\text {Mid }}}{4 m} \\
N_{\text {Mid }}\left(b_{k}\right)=\frac{m-2 d m-b_{\text {West }}-b_{\text {East }}+2 b_{\text {Mid }}}{2 m} \\
N_{\text {East }}\left(b_{k}\right)=\frac{4(v-p)+m-2 d m+6 b_{\text {East }}-2 b_{\text {Mid }}}{4 m}
\end{gathered}
$$

Considering the demand, $T_{k}$ 's problem is to set the optimal benefit level that maximizes its profit mentioned in equation (1). The first order conditions $\left(\frac{d \Pi_{k}}{d b_{k}}=0\right)$ give (Note 21):

$$
\begin{aligned}
& b_{\text {West }}^{*}=\frac{1}{44}\left[\frac{23\left(p-c_{\text {West }}\right)}{\beta_{\text {West }}}+\frac{p-c_{\text {East }}}{\beta_{\text {East }}}+2\left(8 p-3 t+6 d m-8 v+\frac{2\left(p-c_{\text {Mid }}\right)}{\beta_{\text {Mid }}}\right)\right] \\
& b_{\text {Mid }}^{*}=\frac{1}{22}\left[4 p-7 m+14 d m-4 v+\frac{3\left(p-c_{\text {West }}\right)}{\beta_{\text {West }}}+\frac{3\left(p-c_{\text {East }}\right)}{\beta_{\text {East }}}+\frac{12\left(p-c_{\text {Mid }}\right)}{\beta_{\text {Mid }}}\right] \\
& b_{\text {East }}^{*}=\frac{1}{44}\left[\frac{p-c_{\text {West }}}{\beta_{\text {West }}}+\frac{23\left(p-c_{\text {East }}\right)}{\beta_{\text {East }}}+2\left(8 p-3 m+6 d m-8 v+\frac{2\left(p-c_{\text {Mid }}\right)}{\beta_{\text {Mid }}}\right)\right]
\end{aligned}
$$

Since our concern is to get the necessary conditions for the enlargement of the market, we need to compare the position of the marginal consumers at the edges, in each model. If the additional theater enlarges the market we have to satisfy that $y_{1}^{*}<x_{1}^{*}$ and/or $y_{4}^{*}>x_{3}^{*}$.

Proof (2a). Enlargement at the west-side of the market requires that $y_{1}^{*}<x_{1}^{*}$, which needs to satisfy the following disequilibrium:

$$
\begin{gathered}
y_{1}^{*}<x_{1}^{*} \Rightarrow \frac{13 \beta_{\text {East }} \beta_{\text {Mid }}\left(p-c_{\text {West }}\right)+\beta_{\text {West }}\left(140 \beta_{\text {East }}\left(p-c_{\text {Mid }}\right)-97 \beta_{\text {Mid }}\left(p-c_{\text {East }}\right)\right)}{m \beta_{\text {West }} \beta_{\text {East }} \beta_{\text {Mid }}} \\
+\frac{14(4 v-4 p+7 m-14 d m)}{m}>0
\end{gathered}
$$

where the second part of the disequilibrium is positive for sufficiently large $m$ values. However, the first part of the disequilibrium is always positive if $\beta_{\text {Mid }}<\beta_{\text {East }}$ and $c_{\text {Mid }}<c_{\text {East }}$. Q.E.D.

Proof (2b). Enlargement at the east-side of the market requires that $y_{4}^{*}>x_{3}^{*}$, which needs to satify the following disequilibrium:

$$
\begin{gathered}
y_{4}^{*}>x_{3}^{*} \Rightarrow \frac{13 \beta_{\text {West }} \beta_{\text {Mid }}\left(p-c_{\text {East }}\right)+\beta_{\text {East }}\left(140 \beta_{\text {West }}\left(p-c_{\text {Mid }}\right)-97 \beta_{\text {Mid }}\left(p-c_{\text {West }}\right)\right)}{m \beta_{\text {West }} \beta_{\text {East }} \beta_{\text {Mid }}} \\
+\frac{14(4 v-4 p+7 m-14 d m)}{m}>0
\end{gathered}
$$

where the second part of the disequilibrium is positive for sufficiently large $m$ values. However, the first part of the disequilibrium is always positive if $\beta_{\text {Mid }} \leq \beta_{\text {West }}$ and $c_{\text {Mid }} \leq c_{\text {West }}$. Q.E.D. 


\section{Appendix B}

Table B1. Descriptive statistics

\begin{tabular}{llllll}
\hline Variable & Obs & Mean & Std. Dev. & Min & Max \\
\hline$N$ & 599 & 0.24 & 0.21 & 0.01 & 1.21 \\
malls & 599 & 0.23 & 0.30 & 0.00 & 1.00 \\
inc & 599 & 6445 & 2643 & 2112 & 17613 \\
dmovie & 599 & 132 & 317 & 4 & 3864 \\
edu & 599 & 0.42 & 0.08 & 0.22 & 0.68 \\
young & 599 & 0.41 & 0.03 & 0.35 & 0.53 \\
price & 599 & 87.66 & 11.48 & 61.86 & 119.25 \\
\hline
\end{tabular}

\section{Notes}

Note 1. An earlier version of this paper is available at https://papers.ssrn.com/sol3/papers.cfm?abstract_id=2437386

Note 2. Outfit retailers have redesigned their stores to be suitable for mall shopping. The old brands now have larger, fancier stores in the malls. The number of fast food chain branches quadrupled in the last 10 years (http://www.dunya.com/7-fast-food-zinciriturkiye-yolunda-194735h.htm, accessed on 20 January 2015).

Note 3. In 1998 total box office revenue was 40 million dollars, in 2012 total revenue raised to 240 million dollars. (http://www.boxofficeturkiye.com/, accessed on 10 January 2015).

Note 4. The number of new foreign movies has risen 3 times, and domestic movies 5 times from 1998 to 2014. This can be a sign of the fact that, malls attracted different types of watchers to the theaters (http://www.boxofficeturkiye.com/, accessed on 10 January 2015).

Note 5. Rent (total rented area), electricity and heating costs all depend on the number of customers. Hence we focus on the per unit cost.

Note 6. We assume that $v>c_{k}$.

Note 7. The second order conditions require $-\frac{3 \beta_{k}}{t}<0$.

Note 8. See "Why have malls become popular?" section in Part 2.

Note 9. Medyafaresi Rating Reports ( www.medyafaresi.com/reytingler, accessed on 17 February 2015)

Note 10. Box Office reports Turkey.https://boxofficeturkiye.com/tumzaman/

Note 11. We also run one-step system GMM estimators and get very similar results. These estimates are not reported in the text but are available upon request.

Note 12. Cities which have zero or one screen in the beginning of the time period, are excluded from the data set.

Note 13. In Turkey provincial per capita income is only available until 2002. (For Ankara, Istanbul and Izmir, it is continuously available.) Since 2003, TurkStat has reported total and per capita income data on the national and regional levels (26 regions, each region has 3 provinces on average). We used this regional data for the per capita income variable in this study. However, direct usage of these figures i.e. assumption of equal per capita incomes for each province in a particular region could give biased estimates. For this reason, for the years that the provincial income data is available, (1996-2000, 2001 is not included since it was a crisis year.) we calculate that on average, how each province's per capita income is different from the region's per capita income that it belongs to. That is, we calculate coefficients between 0.7 and 1.4 for each province of Turkey according to their differences from their regions' per capita income. Later, we multiply the publicly announced regional data with these coefficients to approximate the provincial income data. Even there could be structural changes which could affect the provinces' relative richness, we still believe that, this method gives trustable approximations considering the short time period of projection (9 years) in which big structural changes are not very probable. (Just for the year 2002, we used a complementary projection using the nation's growth rate.)

Note 14. Test for serial autocorrelation of residuals, $\operatorname{AR}(1)$ and $\operatorname{AR}(2)$, confirm that moment conditions are valid. 
That is $\varepsilon_{i, t}$ is not serially correlated, since the difference of the residuals are characterized by a negative first-order serial correlation and no second-order serial correlation. In addition, Hansen statistics support that the overidentifying moment conditions are valid to have consistent estimates.

Note 15. Hürhaber Newspaper (http://www.hurhaber.com/en-cok-yerlifilm-turkiye-de-izleniyor/haber-616772, accessed on 9 March 2015)

Note 16. One can claim that more domestic movies are featured due to an increase in the viewer share. However, we should remember that the number of domestic movies in period $t$, cannot be affected by the viever share in period $t$. The first variable in period $t$ can only by affected by the second variable in period $t-1$. Movies are produced at least one year before, and featuring dates are determined at least 10 months before the gala. This fact eliminates the problem of endogeneity from the regression. The employed Hausman test on our data supports the non-existence of endogenity as well.

Note 17. In addition, movie ticket prices in mall theaters and city theaters are very similar.

Note 18. On average in Turkey, the mall to all screens ratio has increased by 160 percent in the last 15 years, which has caused the share of viewers in the population to increase by $16 \%$. In the same period in Turkey, the viewer share has increased by 87 percent. That is, roughly 20 percent of the increase is rooted in the mall boom.

Note 19. If we place the additional theater to the left of $T_{\text {West }}$, or to the right of $T_{\text {East }}$, it will enlarge the market by construction. Hence the scenario worth analyzing is the one, in which the additional theater is placed in between the existing theaters.

Note 20. We assume that $v>c_{k}$.

Note 21. The second order conditions require $-\frac{3 \beta_{\text {West }}}{m}<0,-\frac{3 \beta_{\text {East }}}{m}<0$, and $-\frac{2 \beta_{\text {Mid }}}{m}<0$. 